\title{
SISTEM INFORMASI PENYEWAAN LAPANGAN FUTSAL BERBASIS WEB PADA FUTSAL STATION BEKASI
}

\author{
A. Merdekawati ${ }^{1}$, L. K. Rahayu ${ }^{2}$, W. Yulianti ${ }^{3}$ \\ ${ }^{1}$ Sistem Informasi, Universitas Bina Sarana Informatika \\ email: agustiena.atd@bsi.ac.id \\ 2Sistem Informasi, Universitas Bina Sarana Informatika \\ email: \\ ${ }^{3}$ Sistem Informasi, STMIK Nusa Mandiri \\ Email: agustiena.atd@bsi.ac.id, luci.Ikr@bsi.ac.id, windayulianti875@gmail.com,
}

\begin{abstract}
ABSTRAK
Aplikasi penyewaan jadwal lapangan futsal ini digunakan untuk memudahkan penyewa mengetahui jadwal lapangan futsal yang kosong, untuk memberikan kemudahan dalam melakukan proses penyewaan jadwal lapangan futsal tanpa harus datang langsung ke tempat futsal. Pembuatan aplikasi ini dilakukan dengan metode Waterfall. Aplikasi ini di implementasikan dengan bahasa pemograman PHP, database MySQL sebagai media penyimpanan data dan metode pengujian menggunakan black box testing. Tujuan dari penelitian ini adalah menghasilkan sistem informasi penyewaan melalui website. Aplikasi ini dapat digunakan oleh 3 pengguna, yaitu admin, petugas dan penyewa. Admin dapat melakukan olah data lapangan, harga sewa, penyewa, booking, konfirmasi pembayaran dan halaman statis. Penyewa dapat melakukan booking via web, melihat informasi jadwal lapangan dan konfirmasi pembayaran.
\end{abstract}

Kata kunci : Berbasis web, Penyewaan, MySQL, Sistem Informasi.

\begin{abstract}
This futsal schedule rental app is used to facilitate futsal schedule futsal editing, to facilitate futsal schedule rental process without having to go directly to futsal place. Making this application is done by Waterfall method. This application is implemented with PHP programming language, MySQL database as data storage media and testing methods using black box testing. The purpose of this research is the development of rental information system through website. This application can be used by 3 users, namely admin, officers and tenants. Admin can do data, rental price, tenant, booking, payment confirmation and statistics page. Tenants can place orders via the web, view schedule information and confirmation of payment.
\end{abstract}

Keywords: Web-based, Booking, MySQL, Information Systems.

\section{PENDAHULUAN}

Penyewaan lapangan futsal adalah sebuah usaha penyewaan yang menyediakan pelayanan jasa penyewaan lapangan futsal. Saat ini perkembangan tempat penyewaan lapangan futsal sudah semakin berkembang dengan cepat, hal tersebut dapat dilihat sudah semakin banyaknya tempat penyewaan lapangan futsal di berbagai daerah.

Selama ini jika dilihat sistem yang dipakai pada Futsal Station ini dalam proses pelayanan penyewaan lapangan futsal harus datang ketempat futsalnya untuk membooking lapangan futsal, pada pengisian data-data penyewa masih menggunakan kertas catatan. Bukti pembayaran saat ini masih menggunakan banyak kertas sehingga dapat terjadi kehilangan data, sehingga pada saat membuat laporan pembayaran mengalami kesulitan karena data yang tidak lengkap, serta pada saat merekap data, pengelola kesulitan karena ada banyak kertas yang harus dikumpulkan, sehingga perlu ketelitian agar tidak terjadi kesalahan penulisan. 
Menurut [1] Proses bisnis pada tempat sewa lapangan futsal pada umumnya masih mengharuskan pelanggan untuk datang dalam melakukan penyewaan dan mengatur jadwal penyewaan yang diinginkan. Setiap hari petugas melakukan pencatatan penyewaan dan pelanggan ke buku pesanan. Hal ini juga dapat menimbulkan kesalahan dalam pencatatan.

Oleh karena itu dibutuhkannya sebuah sistem yang cukup mudah dioperasikan oleh orang awam sekalipun, sehingga dengan adanya sistem ini mampu mengatasi permasalahan yang ada. Dengan dibuatnya sistem informasi berbasis web ini diharapkan dapat memberikan kemudahan menangani masalah penyewaan lapangan dan pengaturan penjadwalan di Futsal Station. Sehingga dapat mempermudah pengelola lapangan melakukan pendataan dan pembuatan laporan.

\section{A. Sistem}

"Sistem adalah suatu jaringan kerja dari prosedur-prosedur yang saling berhubungan, berkumpul bersama-sama untuk melakukan kegiatan atau untuk melakukan sasaran yang tertentu ".[2]

\section{B. Informasi}

[2] "Informasi adalah data yang diolah menjadi bentuk yang lebih berguna dan lebih berarti bagi penerimanya. Sumber Informasi adalah data. Data kenyataan yang menggambarkan suatu kejadiankejadian dan kesatuan nyata. Kejadian-kejadian (event) adaah kejadian yang terjadi pada saat tertentu".

Menurut Gordon B Davis dalam [2], Informasi adalah data yang telah diolah menjadi suatu bentuk yang penting bagi sipenerima dan mempunyai nilai nyata atau yang dapat dirasakan dalam keputusan-keputusan yang sekarang atau keputusan-keputusan yang akan datang.

\section{Penyewaan}

"Penyewaan adalah cara pemenuhan kebutuhan sarana dan prasarana pendidikan persekolahan dengan jalan pemanfaatan sementara barang milik pihak lain untuk kepentingan sekolah dengan cara membayar berdasarkan perjanjian sewa-menyewa".[3]

\section{Futsal}

Futsal saat ini sudah berkembang di Indonesia. Futsal yaitu sejenis permainan bola kaki yang dimainkan secara beregu, dengan cepat, dinamis, serta menggunakan lapangan yang kecil.

\section{E. Konsep Dasar Pemrograman}

"Adobe Dreamweaver merupakan aplikasi pengembang yang berfungsi untuk mendesain web yang dibuat, dikembangkan, dan diproduksi oleh Adobe System" [4]. Versi Adobe Dreamweaver saat ini adalah Adobe Dreamweaver CS6.

[5], "PHP merupakan bahasa pemrograman berjenis server-side. Dengan demikian Php akan diproses oleh server yang hasil olahannya akan dikirim kembali ke browser. Oleh karena itu, salah satu tool yang harus tersedia sebelum memulai pemrograman PHP adalah server".

"JavaScript adalah bahasa (pemrograman) yang hebat, meskipun cenderung sulit untuk dipahami, akan tetapi kemampuan inti yang dimiliki oleh JavaScript sangat menarik untuk didalami”. Dengan JavaScipt anda dapat membuat aplikasi-aplikasi hebat seperti Google Maps. Java Script telah merubah pandangan dunia terhadap internet (web).[6]

"MySql adalah RDBMS yang cepat dan mudah digunakan, serta sudah banyak digunakan untuk berbagai kebutuhan".[7]

"XAMPP adalah paket program berbasis web yang didalamnya berisi software apache, PHP, dan database MySQL". "XAMPP merupakan paket PHP dan MySQL berbasis open source, yang dapat digunakan sebagai tool pembantu pengembangan aplikasi berbasis PHP“..[8]

\section{F. SDLC (Software Development Life Cycle)}

Menurut Sukamto dan Shalahudin dalam [9] menyatakan bahwa :

SDLC (Software Development Life Cycle) atau sering disebut juga System Development Life Cycle adalah proses mengembangkan atau mengubah suatu sistem perangkat lunak dengan menggunakan model-model dan metodologi yang digunakan orang untuk mengembangkan sistemsistem perangkat lunak sebelumnya (berdasarkan best practice atau cara-cara yang teruji baik). 
Tahapan-tahapan metode penelitian yang ada pada model waterfall, sebagai berikut: (Sukamto dan Shalahudin dalam [9])

a. Analisa Kebutuhan Perangkat Lunak

Merupakan proses pengumpulan kebutuhan dilakukan secara intensif untuk menspesifikasikan kebutuhan perangkat lunak agar dapat dipahami perangkat lunak seperti apa yang dibutuhkan oleh user. Spesifikasi kebutuhan perangkat lunak pada tahap ini perlu untuk didokumentasikan.

b. Desain.

Desain perangkat lunak adalah proses multi langkah yang fokus pada desain pembuatan program perangkat lunak, termasuk struktur data, arsitektur perangkat lunak, representasi antarmuka, dan prosedur pengkodean. Tahap ini mentranslasikebutuhan perangkat lunak dari tahap analisa kebutuhan kerepresentasi desain agar dapat diimplementasikan menjadi program pada tahap selanjutnya.

c. Pembuatan kode program

Desain harus ditranslasikan ke dalam program perangkat lunak. Hasil dari tahap ini adalah program komputer sesuai dengan desain yang telah dibuat pada tahap desain.

d. Pengujian

Pengujian fokus pada perangkat lunak secara dari segi logik dan fungsional dan memastikan bahwa semua bagian sudah diuji. Hal ini dilakukan untuk meminimalisir kesalahan (error) dan memastikan keluaran yang dihasilkan sesuai dengan yang diinginkan.

e. Pendukung (Support) atau Pemeliharaan (maintenance)

Tidak menutup kemungkinan sebuah perangkat lunak mengalami perubahan ketika sudah dikirimkan ke user. Perubahan bisa terjadi karena adanya kesalahan yang muncul dan tidak terdeteksi daat pengujian atau perangkat lunak harus beradaptasi dengan lingkungan baru. Tahap pendukung atau pemeliharaan dapat mengulangi proses pengembangan mulai dari analisis spesifikasi untuk perubahan perangkat lunakyang sudah ada, tapi tidak untuk membuat perangkat lunak baru.

\section{METODE PENELITIAN}

Teknik yang digunakan untuk mengumpulkan data dalam penelitian ini adalah sebagai berikut :

a. Pengamatan (Observation)

Pengamatan, penulis disini langsung terjun ke Futsal Station Bekasi untuk melakukan pengecekan terhadap objek yang diteliti dilapangan.

b. Wawancara (Interview)

Wawancara, Wawancara merupakan proses tanya jawab langsung kepada orang yang mengetahui tentang permasalahan yang sedang diamati. Penulis disini mewawancarai Bapak Mulyadi selaku Pengelola dan Bapak Thaqim selaku penjaga.

c. Studi Pustaka (Library Research)

Penulis melakukan pengumpulan bahan-bahan yang berkaitan dengan judul dengan membaca buku-buku. Sebagai referensi, peneliti juga memanfaatkan teknologi untuk membuka wawasan dan pengetahuan mengenai apa yang akan dikerjakan.

Selanjutnya, untuk tahap pengembangan sistemnya seperti dibawah ini :

a. Analisa Kebutuhan Sistem

Proses pengumpulan kebutuhan yaitu penulis mengidentifikasi masalah, menganalisa sistem yang sedang berjalan termasuk kekurangannya, menganalisis kebutuhan user, mengumpulkan data selama riset pada Futsal Station Bekasi sebagai bahan pembuatan skripsi. Mengumpulkan dokumendokumen yang diperlukan untuk merancang sistem informasi penyewaan lapangan futsal, proses pembayaran hingga proses laporan. Dokumen ini akan menjadi acuan penulis untuk melakukan tahapan berikutnya.

b. Desain

Dalam membangun sistem dengan membuat perancangan yang berfokus kepada penyajian berupa desain basis data yaitu Entity Relationship Diagram (ERD) dan Logical Relational Structure (LRS). Software Architecture untuk memodelkan sistem dirancang menggunakan Unified Modeling Language (UML) yang akan digambarkan memalui beberapa diagram seperti use case diagram, activity diagram, deployment diagram dan component diagram. Dan merancang bentuk tampilan grafis yang berhubungan langsung dengan pengguna yang akan memudahkan pengoperasian dari perangkat tersebut. 


\section{c. Code generation}

Pada tahap ini, penulis menggunakan bahasa pemrograman PHP dan database yang digunakan adalah MYSQL dalam perancangan web sistem informasi penyewaan lapangan futsal. Teknik pemrograman yang digunakan adalah pemrograman berorientasi objek. Hasil dari tahap ini adalah program komputer dengan desain yang telah dibuat pada tahap desain.

d. Testing

Pada tahap ini, pengujian sistem yang dibuat menggunakan blackbox testing. Hal ini dilakukan untuk meminimalisir kesalahan (error) dan memastikan keluaran yang dihasilkan sesuai dengan yang diinginkan.

e. Support

Dalam mendukung sistem ini di perlukan perangkat komputer yang memadai baik perangkat keras dan perangkat lunak. Perangkat keras yang dibutuhkan diantaranya : hardisk, processor, memory, keyboard, mouse, monitor, printer. Dan untuk perangkat lunak yang dibuthkan yaitu : XAMPP, Adobe Dreamweaver CS5 dan MYSQL.

\section{HASIL DAN PEMBAHASAN}

\section{A. Proses Bisnis Sistem Berjalan Futsal Station}

Futsal Station merupakan usaha yang bergerak dibidang penyewaan lapangan. Dalam kegiatan penyewaan lapangan diawali dengan pelanggan datang ke Futsal Station lalu pelanggan melakukan booking lapangan dengan memberi informasi untuk tanggal berapa, jam berapa, atas nama siapa dan lapangan mana yang akan dibooking. Pelanggan membayar dp booking lapangan kepada petugas lalu petugas akan mencatat data bookingan pada lembar booking harian kemudian petugas akan membuat kwitansi dp untuk diberikan kepada pelanggan sebagai bukti booking. Pada saat tanggal main, pelanggan melapor pada petugas dengan membawa bukti kwitansi dp serta membayar sisa pembayaran, kemudian petugas akan membuatkan kwitansi pelunasan yang akan diberikan kepada pelanggan. Jika semua selesai, pengelola akan merekap data booking harian dan membuat laporan keuangan yang akan diberikan kepada pemilik. Berikut activity diagram dari proses berjalan futsal station :

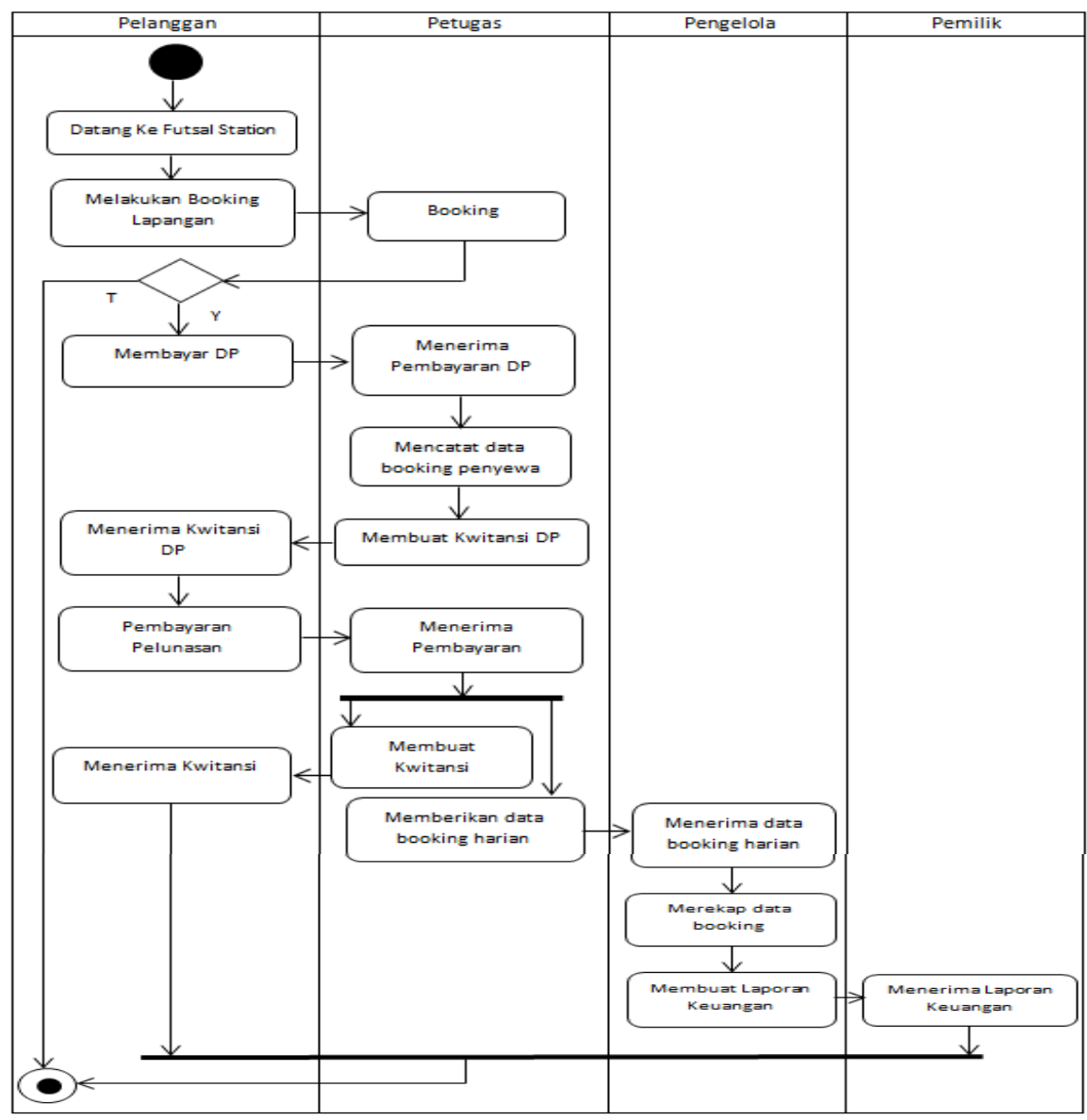


Gambar 1. Activity Diagram Penyewaan Lapangan Futsal

Dalam spesifikasi sistem berjalan ini akan dijelaskan mengenai dokumen-dokumen yang terdapat dalam proses pencatatan datanya, dokumen-dokumen tersebut terdiri atas dokumen masukan dan dokumen keluaran.
1. Surat : Lembar Booking
Fungsi : Untuk mencatat data booking
Sumber : Petugas
Tujuan : Pelanggan
Media : Kertas
Frekuensi : Setiap terjadi penyewaan
Format : Lampiran A-1
2. Surat : Kwitansi
Fungsi :Sebagaibukti pembayaran
Sumber : Petugas
Tujuan : Pelanggan
Media : Kertas
Frekuensi :Setiap terjadi pembayaran penyewaan
Format : Lampiran A-2
3. Surat : Laporan
Fungsi : Untuk mengetahui pemasukan keuangan
Sumber : Pengelola
Tujuan : Pemilik
Media : Kertas
Frekuensi : Setiap sebulan sekali
Format : Lampiran A-3

\section{B. Sistem Yang Diusulkan Pada Futsal Station}

Sistem penyewaan adalah sistem penyewaan secara online berbasis web dimana penyewa dan pemilik tidak bertatap muka secara langsung. Calon penyewa melakukan booking melalui media browser. Berikut ini spesifikasi kebutuhan dari sistem.

Halaman Front-page:

A.1 User dapat melihat beranda

A.2 User dapat melihat tentang kami

A.3 User dapat melihat panduan

A.4 User dapat melihat daftar lapangan

A.5 User dapat melakukan booking lapangan

A.6 User dapat melakukan konfirmasi pembayaran

A.7 User dapat melakukan cek booking

Halaman Admin :

B.1 Admin dapat melakukan Login

B.2 Admin dapat menganti password

B.3 Admin dapat mengelola data penyewa

B.4 Admin dapat mengelola data petugas

B.5 Admin dapat mengelola data lapangan

B.6 Admin dapat mengelola data booking

B.7 Admin dapat mengelola halaman statis

B.8 Admin dapat melihat laporan

\section{c. Use Case}

\section{a) Use Case Diagram Halaman User}

Disini user dapat melihat beranda, tentang kami, panduan, daftar lapangan, melakukan booking dan cek booking. 


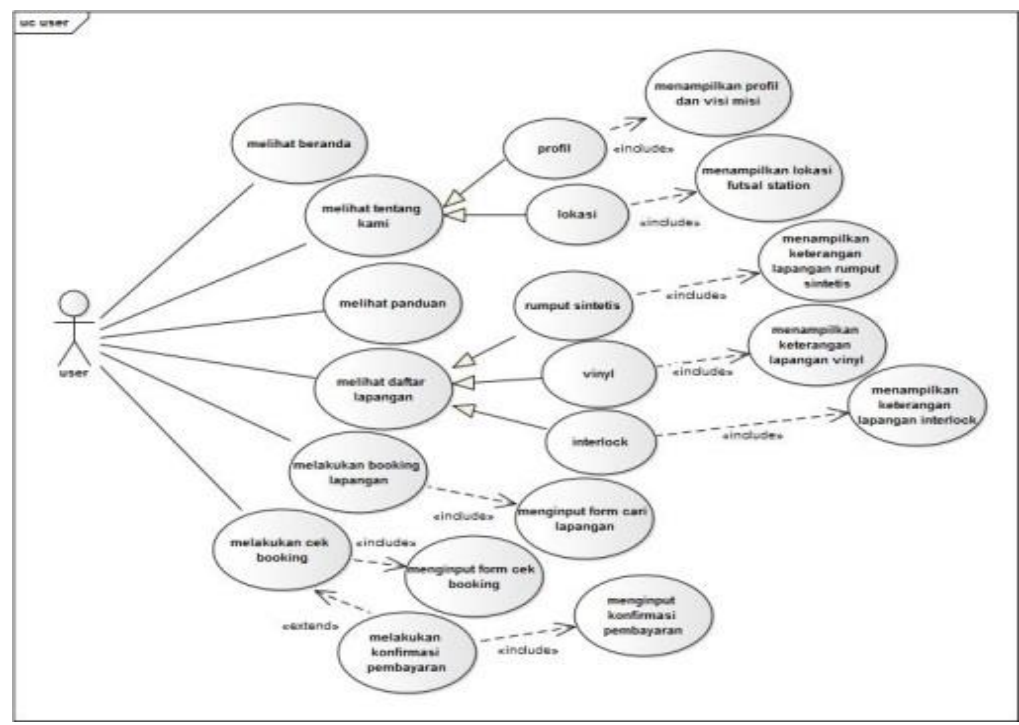

Gambar 2. Use Case Diagram Halaman User

\section{b) Use Case Diagram Halaman Admin}

Pada halaman admin, admin melakukan login dan dapat melihat beranda, ubah password, lihat data penyewa data petugas, data lapangan, data booking, halaman statis dan lihat laporan.

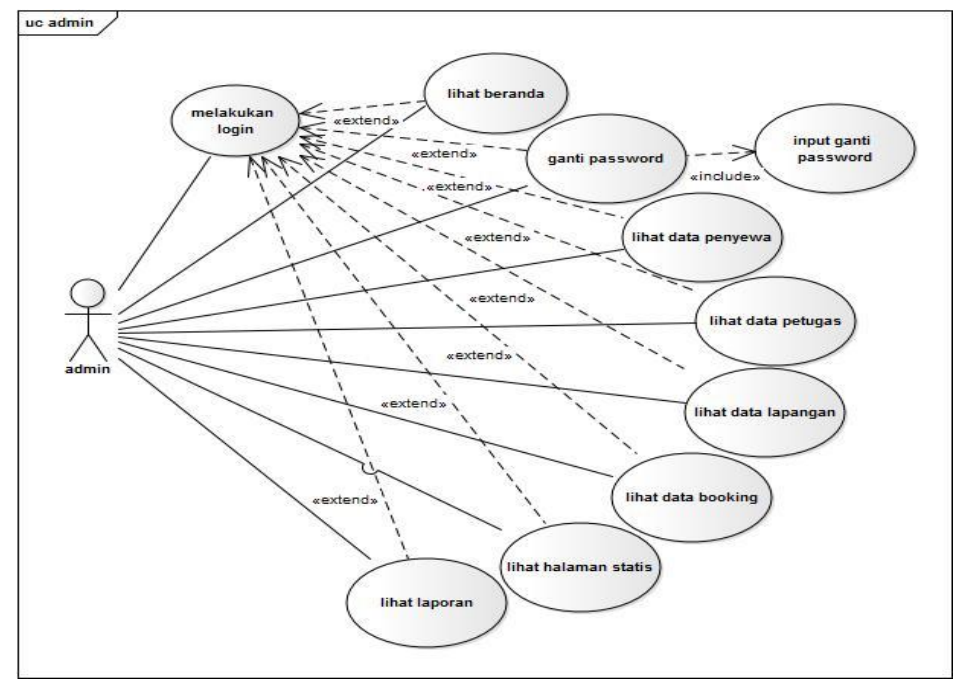

Gambar 3. Use Case Diagram Halaman Admin

\section{Activity Diagram}

a) Activity Diagram Booking Lapangan Halaman User

Dibawah ini merupakan alur booking dari sisi user. 


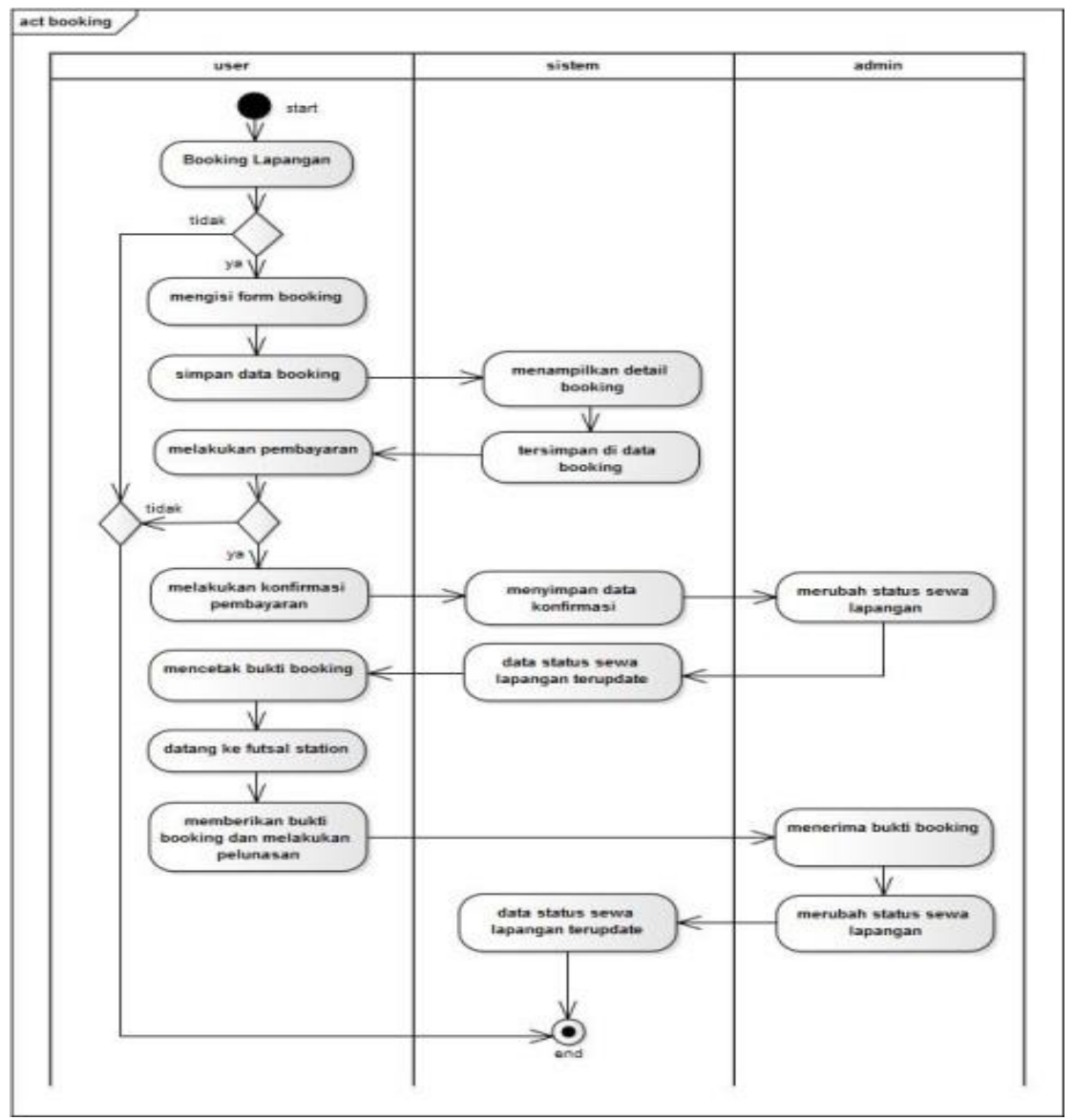

Gambar 4. Activity Diagram Booking Lapangan Halaman User

\section{b) Activity Diagram Admin}

Dibawah ini merupakan alur kerja sistem dari sisi admin. 


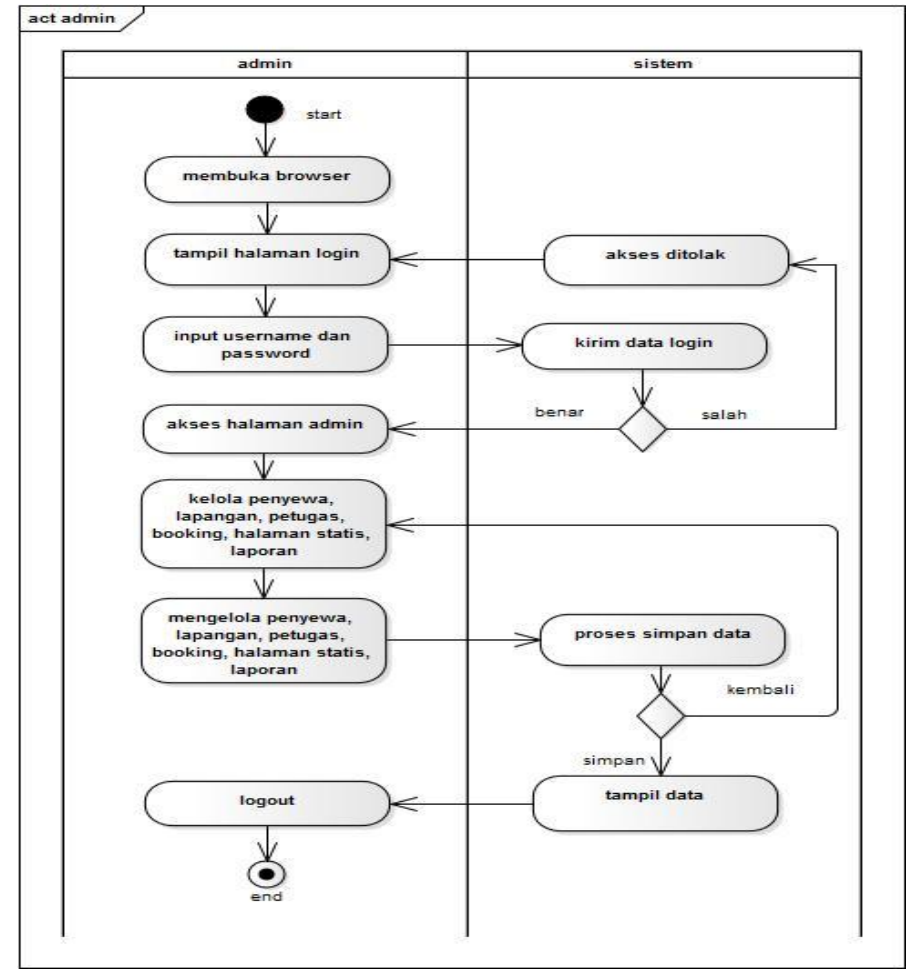

Gambar 5. Activity Diagram Admin

\section{c) Activity Diagram Laporan}

Dibawah ini merupakan alur dimana ingin mencetak laporan.

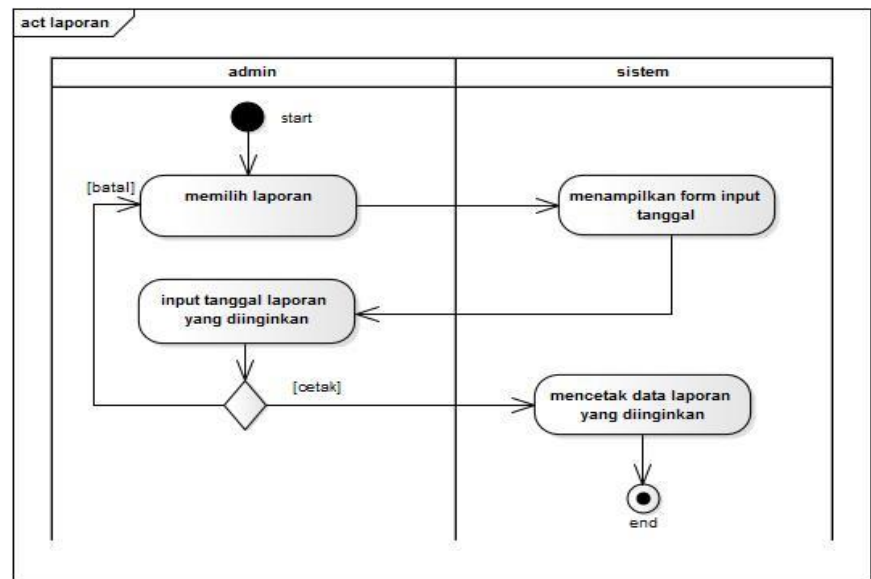

Gambar 6. Activity Diagram Laporan

\section{E. Desain Database}

a) Entity Relationship Diagram

Disini penyewa dapat melakukan banyak booking dan penyewa dapat melakukan satu konfirmasi bayar, lalu satu transaksi booking memiliki satu lapangan dan satu transaksi booking memiliki satu konfirmasi bayar. 


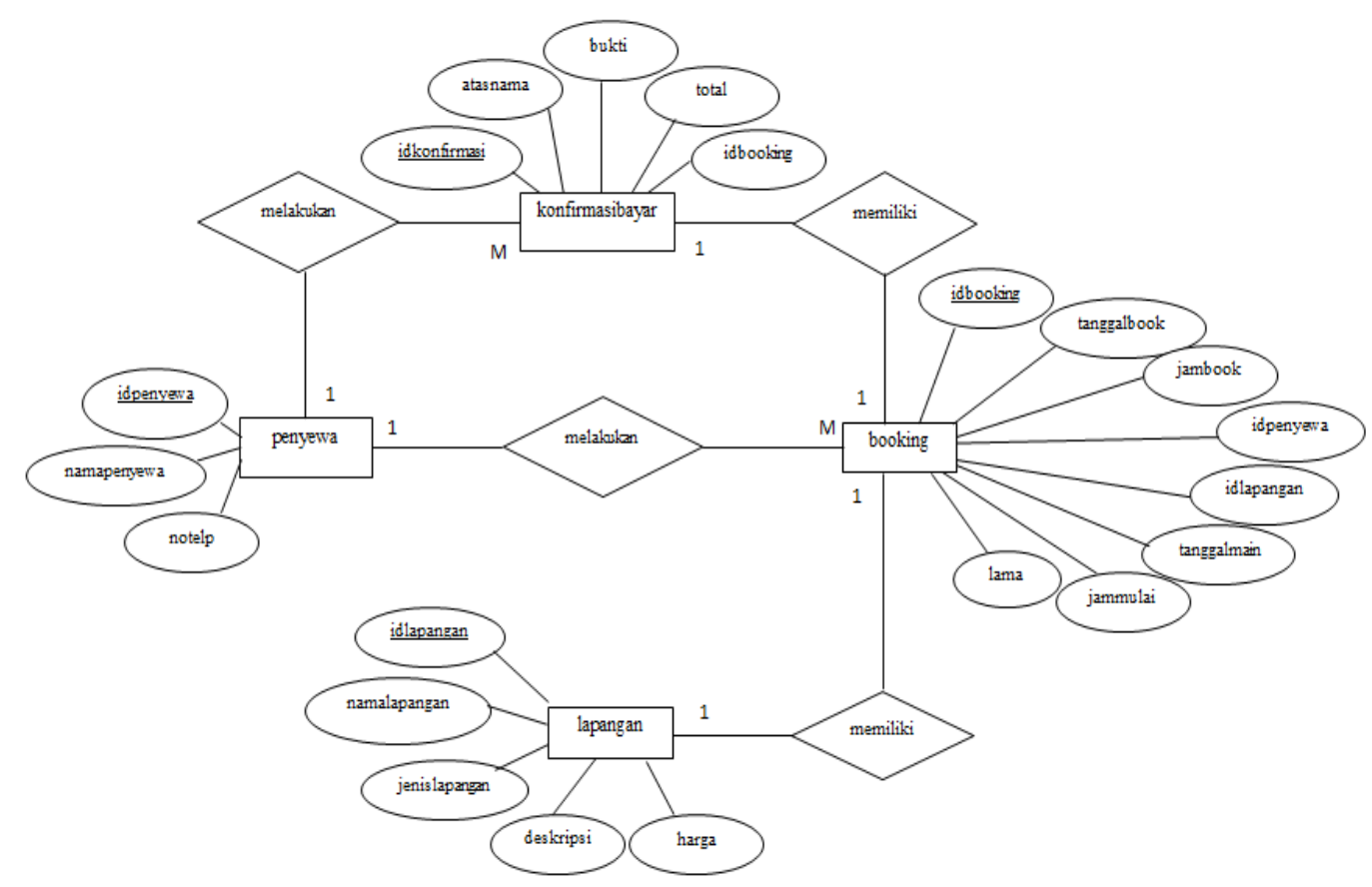

Gambar 7. Entity Relationship Diagram

\section{F. User Interface}

a) Tampilan Halaman Beranda

Halaman beranda merupakan halaman utama website.

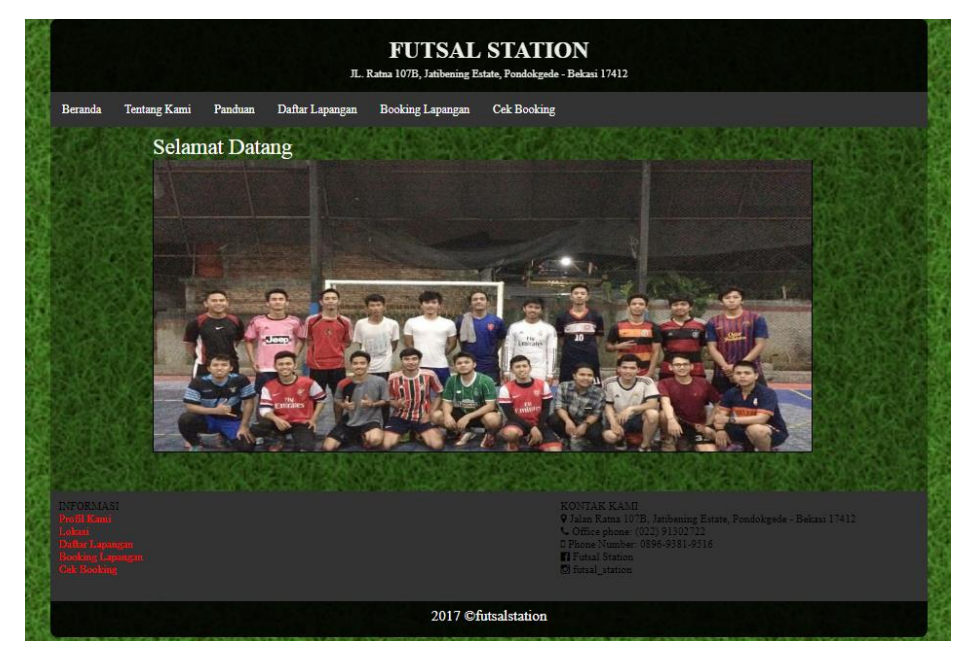

Gambar 8. Tampilan Halaman Beranda

\section{b) Tampilan Halaman Cari Lapangan}

Pada halaman ini berisikan tentang input data pencarian tanggal, lapangan, jam dan lama main yang ingin di booking. 


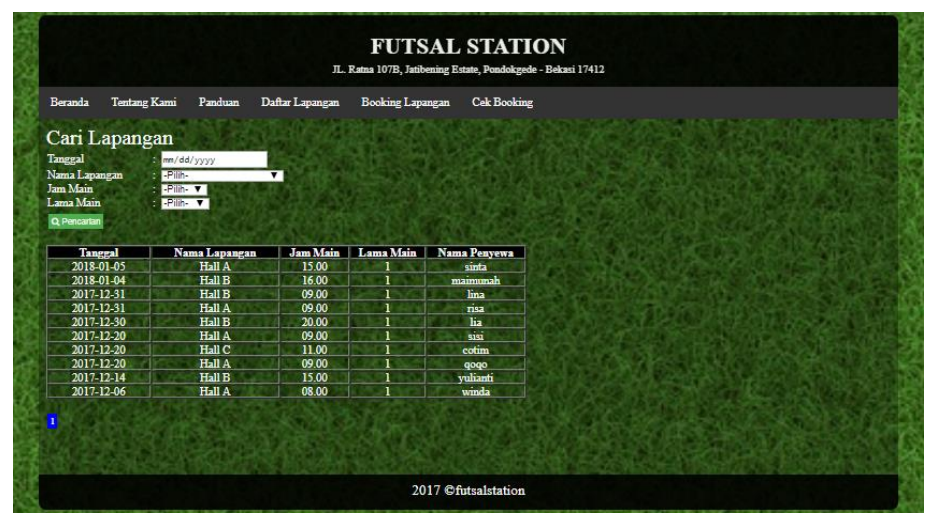

Gambar 9. Tampilan Halaman Cari Lapangan

\section{c) Tampilan Halaman Booking Lapangan}

Pada halaman ini berisikan tentang input data booking yang ada di Futsal Station. Sebelum itu penyewa harus melakukan pencarian lapangan dulu baru melakukan booking lapangan yang dipilih.

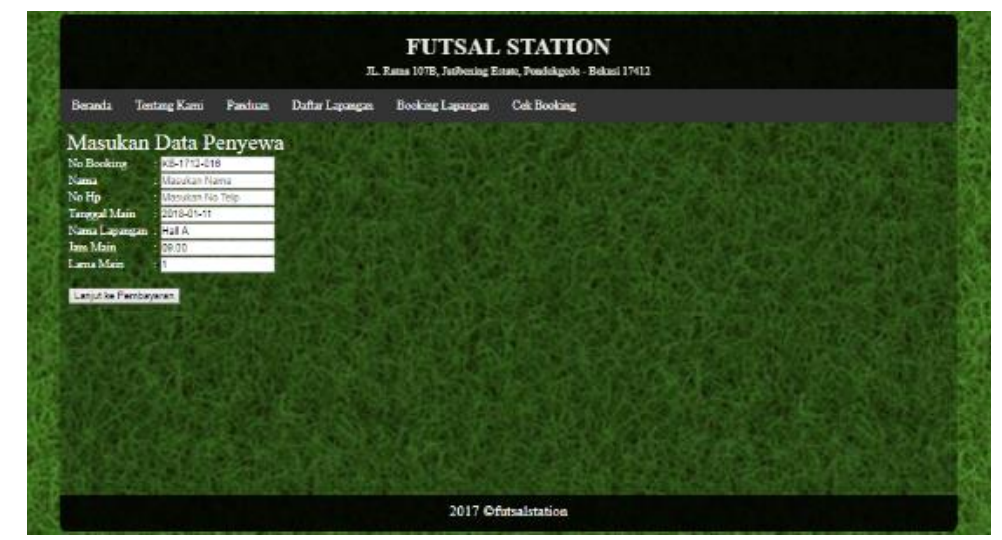

Gambar 10. Tampilan Halaman Booking Lapangan

\section{d) Tampilan Halaman Cek Booking}

Pada halaman ini berisikan input data booking sebelumnya untuk melakukan konfirmasi pembayaran dan cetak bukti booking.

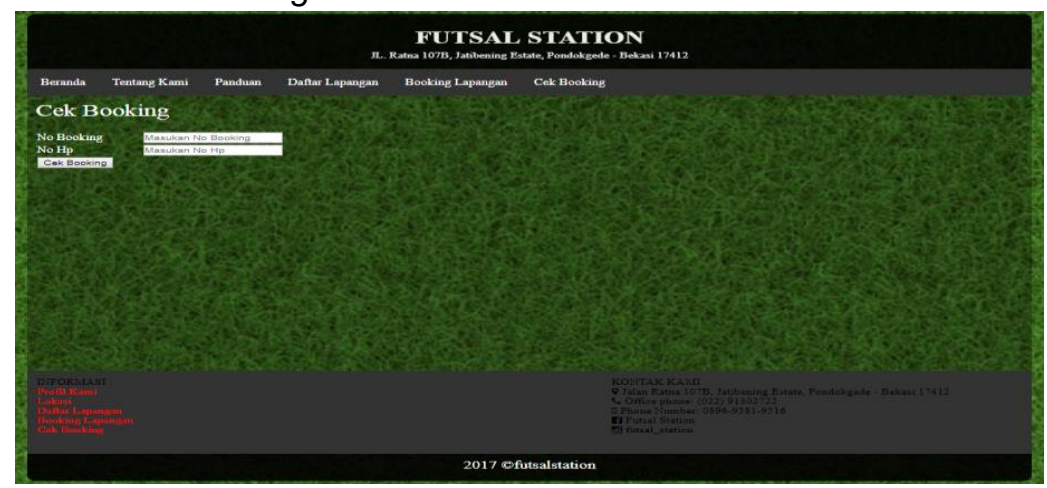

Gambar 11. Tampilan Halaman Cek Booking Lapangan

\section{e) Tampilan Halaman Login Admin}

Halaman login merupakan halaman yang digunakan admin untuk masuk kedalam halaman menu admin. Admin harus mengisikan username dan password. 


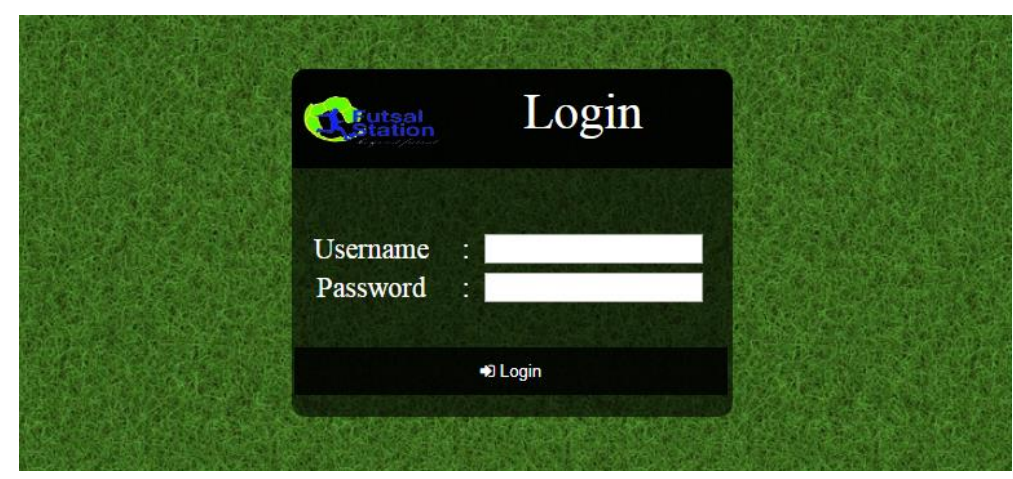

Gambar 12. Tampilan Halaman Login Admin

\section{G. Testing (Pengujian)}

Pengujian yang digunakan pada penelitian ini menggunakan Blackbox Testing. Berikut hasil dari pengujian yang dilakukan :

Tabel 1.Hasil Pengujian Black Box Testing Form Booking

\begin{tabular}{|c|c|c|c|c|c|}
\hline No & $\begin{array}{l}\text { Skenario } \\
\text { Pengujian }\end{array}$ & Test case & Hasil yang diharapkan & $\begin{array}{c}\text { Hasil } \\
\text { Pengujian }\end{array}$ & Kesimpulan \\
\hline 1 & $\begin{array}{l}\text { Mengosongkan } \\
\text { semua isian } \\
\text { data pada form } \\
\text { booking, lalu } \\
\text { mengklik tombol } \\
\text { "Booking". }\end{array}$ & $\begin{array}{l}\text { Nama : (kosong) } \\
\text { No } \mathrm{Hp}: \text { (kosong) }\end{array}$ & $\begin{array}{l}\text { Sistem akan menolak dan } \\
\text { menampilkan "Nama } \\
\text { penyewa tidak boleh } \\
\text { kosong dan No telp tidak } \\
\text { boleh kosong ". }\end{array}$ & $\begin{array}{l}\text { Sesuai } \\
\text { harapan }\end{array}$ & Valid \\
\hline 2 & $\begin{array}{l}\text { Hanya mengisi } \\
\text { Nama Penyewa } \\
\text { lalu mengklik } \\
\text { tombol } \\
\text { "Booking". }\end{array}$ & $\begin{array}{l}\text { Nama : winda } \\
\text { No hp : (kosong) }\end{array}$ & $\begin{array}{l}\text { Sistem akan menolak dan } \\
\text { menampilkan "No telp tidak } \\
\text { boleh kosong". }\end{array}$ & $\begin{array}{c}\text { Sesuai } \\
\text { harapan }\end{array}$ & Valid \\
\hline 3 & $\begin{array}{l}\text { Hanya mengisi } \\
\text { No Telp lalu } \\
\text { mengklik tombol } \\
\text { "Booking". }\end{array}$ & $\begin{array}{l}\text { Nama : (kosong) } \\
\text { No hp : } \\
089693819516\end{array}$ & $\begin{array}{l}\text { Sistem akan menolak dan } \\
\text { menampilkan "Nama } \\
\text { Penyewa tidak boleh } \\
\text { kosong". }\end{array}$ & $\begin{array}{l}\text { Sesuai } \\
\text { harapan }\end{array}$ & Valid \\
\hline 4 & $\begin{array}{l}\text { Mengisi No Telp } \\
\text { dengan huruf } \\
\text { lalu mengklik } \\
\text { tombol } \\
\text { "Booking". }\end{array}$ & $\begin{array}{l}\text { Nama : winda } \\
\text { No hp : } \\
\text { 08969tyghj }\end{array}$ & $\begin{array}{l}\text { Sistem akan menolak dan } \\
\text { menampilkan "Penulisan } \\
\text { No telp salah". }\end{array}$ & $\begin{array}{l}\text { Sesuai } \\
\text { harapan }\end{array}$ & Valid \\
\hline 5 & $\begin{array}{l}\text { Menginput } \\
\text { semua isian } \\
\text { data lalu } \\
\text { mengklik tombol } \\
\text { "Booking". }\end{array}$ & $\begin{array}{l}\text { Nama : winda } \\
\text { No hp : } \\
089693819516\end{array}$ & $\begin{array}{l}\text { Sistem akan menerima dan } \\
\text { menampikan menu detail } \\
\text { booking }\end{array}$ & $\begin{array}{l}\text { Sesuai } \\
\text { harapan }\end{array}$ & Valid \\
\hline
\end{tabular}




\section{KESIMPULAN DAN SARAN}

Berdasarkan dari hasil perancangan tentang sistem informasi penyewaan lapangan futsal pada futsal station yang diusulkan, maka penulis dapat menarik kesimpulan bahwa :

1. Dengan adanya sistem informasi penyewaan lapangan futsal berbasis web ini dapat membantu mempromosikan Futsal Station kepada kalangan umum.

2. Dengan dibuatnya sistem berbasis web ini penyewa dapat mem-booking lapangan futsal secara online, dimana penyewa tidak perlu datang langsung ke futsal station untuk melakukan penyewaan.

3. Mempermudah dalam hal penyajian informasi yang akurat.

4. Dengan adanya sistem informasi penyewaaan lapangan futsal ini membantu petugas dalam pengolahan data.

Adapun beberapa saran yang dapat penulis sampaikan berkaitan dengan penelitian ini yaitu sebagai berikut :

1. Sistem bisa dikembangan lebih lanjut dengan menambahkan database yang lebih lengkap sehingga menghasilkan informasi yang lebih detail.

2. Aplikasi web ini masih sangat sederhana maka untuk pengembangan selanjutnya disarankan untuk menambahkan fitur yang menarik dan unik.

3. Untuk lebih menyempurnakan sistem informasi ini diharapkan kedepannya penyewa dapat melakukan booking untuk memilih lebih dari satu lapangan.

\section{DAFTAR PUSTAKA}

[1] N. A. Rahma, "Aplikasi Penyewaan Lapangan Futsal Berbasis WEB dan SMS Gateway," eProceeding Appl. Sci., vol. 1, no. 1, p. 6, 2015.

[2] J. Hutahaean, "Konsep Sistem Informasi," Jakarta: PT. Elex Media Komputindo, 2014.

[3] I. Indrawan, "Pengantar Manajemen Sarana dan Prasarana Sekolah," Yogyakarta: Deepublish, 2015.

[4] R. Mandar, "Solusi Tepat Menjadi Pakar Adobe Dreamweaver CS6," Jakarta : PT. Elex Media Komputindo, 2017.

[5] J. Enterprise, "PHP Komplet," PHP Komplet, 2017.

[6] Madcoms, "Pemrograman PHP Dan MySQL Untuk Pemula," Bandung: Andi, 2016.

[7] J. Enterprise, "MySQL untuk Pemula," Jakarta: PT. Elex Media Komputindo, 2014.

[8] S. Riyanto, "Kupas Tuntas Web Responsive," Jakarta: PT. Elex Media Komputindo, 2014. .

[9] A. Merdekawati, "Rancang Bangun Penjualan Brankas Berbasis Web Pada Pt. Persindo Pertiwi Agung Jakarta," J. Pendidik. Teknol. dan Kejuru., vol. 15, no. 2, pp. 265-276, 2018. 